\title{
Inferior Phrenic Arteries and Their Branches, Their Anatomy and Possible Clinical Importance: An Experimental Cadaver Study
}

\author{
İlke Ali Gürses, Özcan Gayretli, Ayşin Kale, Adnan Öztürk, Ahmet Usta, Kayıhan Şahinoğlu
}

Department of Anatomy, İstanbul University, İstanbul Faculty of Medicine, İstanbul, Turkey

Background: Transcatheter arterial chemoembolization is a common treatment for patients with inoperable hepatocellular carcinoma. If the carcinoma is advanced or the main arterial supply, the hepatic artery, is occluded, extrahepatic collateral arteries may develop. Both, right and left inferior phrenic arteries (RIPA and LIPA) are the most frequent and important among these collaterals. However, the topographic anatomy of these arteries has not been described in detail in anatomy textbooks, atlases and most previous reports.

Aims: To investigate the anatomy and branching patterns of RIPA and LIPA on cadavers and compare our results with the literature.

Study Design: Descriptive study.

Methods: We bilaterally dissected 24 male and 2 female cadavers aged between 49 and 88 years for this study.
Results: The RIPA and LIPA originated as a common trunk in 5 cadavers. The RIPA originated from the abdominal aorta in 13 sides, the renal artery in 2 sides, the coeliac trunk in 1 side and the left gastric artery in 1 side. The LIPA originated from the abdominal aorta in 9 sides and the coeliac trunk in 6 sides. In 6 cadavers, the ascending and posterior branches of the LIPA had different sources of origin.

Conclusion: As both the RIPA and LIPA represent the half of all extrahepatic arterial collaterals to hepatocellular carcinomas, their anatomy gains importance not only for anatomists but interventional radiologists as well.

Keywords: Ascending branch, descending branch, inferior phrenic arteries, left inferior phrenic artery
Surgery is the preferred treatment method for hepatic malignancies. Due to advanced tumor stage and accompanying cirrhosis, most cases are considered inoperable at the time of diagnosis (1). It is well known that the blood supply to liver malignancies is typically arterial, unlike the parenchyma, which is supplied by the portal vein (2). Apart from being the main arterial supply to the diaphragm, the right and left inferior phrenic arteries (RIPA and LIPA), are extrahepatic collateral arterial pathways that supply hepatic malignancies, because they neighbor hepatic segments as they traverse the bare area of the liver $(3,4)$. Among the arterial pathways that supply liver malignan- cies, both RIPA and LIPA constitute nearly half of the collaterals, with RIPA being the most common and LIPA being the 4th or $6^{\text {th }}$ most common $(5,6)$. Therefore, both RIPA and LIPA are used during transcatheter arterial chemoembolization of liver malignancies (5-7). Furthermore, LIPA gives branches that supply the stomach and esophagus and can be a source of arterial bleeding at the esophagogastric junction (8-12).

In this study, we aimed to investigate the anatomy of the inferior phrenic arteries - with special reference to the branches of the LIPA - and to outline their clinical importance with anatomical pitfalls which we believe may help interventional radiologists.

This study was presented as an oral presentation at the $13^{\text {th }}$ National Anatomy Congress, Kyrenia, Turkish Republic of Northern Cyprus, 2010 and as a poster presentation at the $29^{\text {th }}$ Annual Meeting of the AACA, 8-13 July 2012, True Blue, Grenada.

Address for Correspondence: Dr. İlke Ali Gürses, Department of Anatomy, İstanbul University, İstanbul Faculty of Medicine, İstanbul, Turkey

Phone: +90 5332152080 e-mail: iagurses@gmail.com

Received: 18.09.2013 Accepted: 11.12.2014 • DOI: 10.5152/balkanmedj.2015.150052

Available at www.balkanmedicaljournal.org 


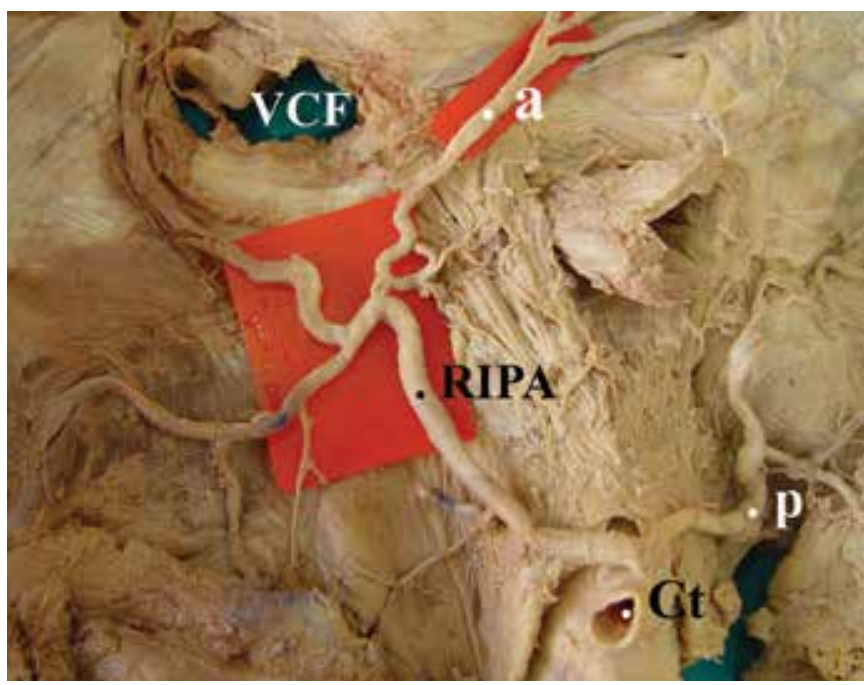

FIG. 1. Origin of the RIPA (RIPA) and the posterior branch of the LIPA (p) from the coeliac trunk (Ct) as a common trunk. The ascending branch of the LIPA (a) arises from the RIPA and passes anterior to the esophagus (E). VCF: Vena caval foramen.

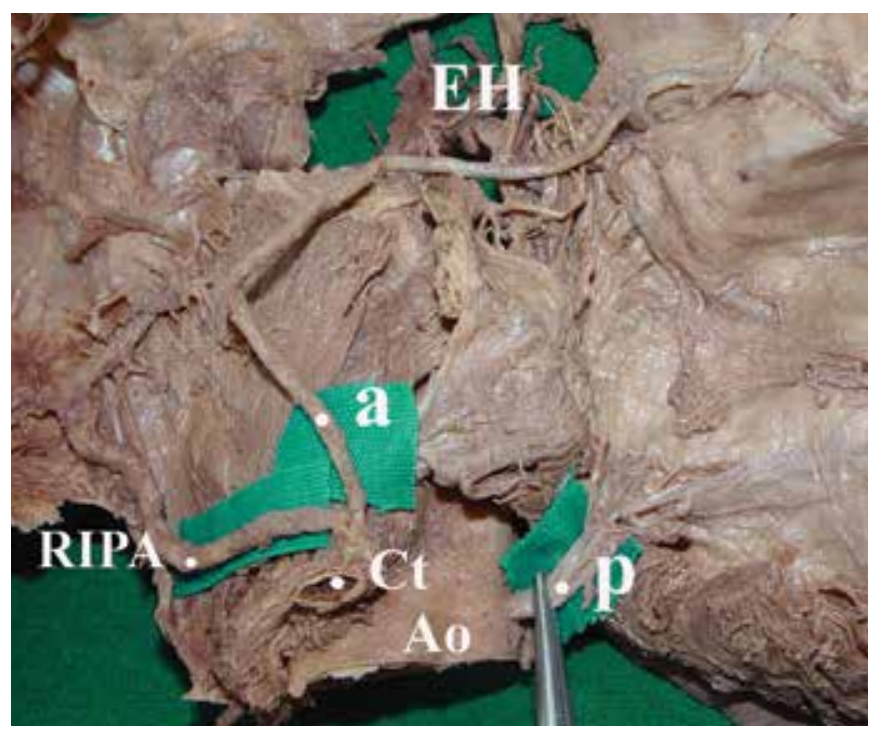

FIG. 2. Origin of the RIPA (RIPA) and the ascending branch of the LIPA (a) from the coeliac trunk (Ct) as a common trunk. The posterior branch of the LIPA (p) arises from the abdominal aorta (Ao). EH: Esophageal hiatus.

\section{MATERIALS and METHODS}

The upper abdominal regions of 24 male and 2 female cadavers, aged between 49 and 88 years, used for gross anatomy dissection course for undergraduate medical students were dissected bilaterally. The cadavers were perfused with formaldehyde-phenol-glycerin-ethanol mixture. No evidence of trauma, gross pathology or prior surgery regarding upper abdominal organs were noticed. After determining the origin of the RIPA and LIPA, the diaphragm, abdominal aorta, right and left kidneys along with the neighboring suprarenal glands were resected and further dissections were carried out to demonstrate the course of the arteries and their branches.

A digital camera (DSC-F707, Sony Co., Japan) was used to document the variations observed and all images were processed with a graphics editing program (Adobe Photoshop CS2, Adobe Systems Inc. 2005, USA).

At our Institution, IRB approval is not required for anatomic studies performed on cadavers.

We used a statistical editing software (IBM SPSS Statistics for Windows, v. 21.0. Armonk, NY; IBM Corp.) for analyzing the acquired data.

\section{RESULTS}

The RIPA and LIPA originated as a common trunk from the abdominal aorta in 3 cadavers $(3 / 26,11.53 \%)$ and from the coeliac trunk in 2 cadavers $(2 / 26,7.69 \%)$.

The RIPA originated from the abdominal aorta in 13 sides $(13 / 26,50 \%)$, from the right renal artery in 2 sides $(2 / 26$, $7.69 \%)$, from the coeliac trunk in 1 side $(1 / 26,3.85 \%)$ and from the left gastric artery in 1 side $(1 / 26,3.85 \%)$.

The LIPA originated from the abdominal aorta in 9 sides $(9 / 26,34.61 \%)$ and from the coeliac trunk in 6 sides $(6 / 26$, 23.07\%).

As the RIPA and LIPA ascended anterior to the crura of the diaphragm, they gave two main branches in all cadavers. The posterior branch traversed parallel to the lower border of the lumbar part of the diaphragm, where the ascending branch arose from the level of the vena caval and esophageal foramina on right and left sides.

In 6 cadavers 6/26, 23.07\%), the ascending and the posterior branches of the LIPA arose from separate origins. In 3 cadavers $(3 / 26,11.53 \%)$, the posterior branch and the RIPA originated from the coeliac trunk as a common trunk and the ascending branch arose from the RIPA (Figure 1). In all 3 cases, the ascending branches passed anterior to the esophagus. In 1 cadaver (1/26, 3.85\%) the ascending branch and the RIPA arose from the coeliac trunk as a common trunk and the posterior branch originated from the abdominal aorta (Figure 2). In 1 side $(1 / 26,3.85 \%)$, the ascending branch originated from the coeliac trunk and the posterior branch arose from the abdominal aorta (Figure 3). In 1 side $(1 / 26,3.85 \%)$, the posterior branch originated from the coeliac trunk and the ascending branch arose from an accessory left hepatic artery and passed anterior to the esophagus (Figure 4). Table 1 summarizes the origins of the RIPA, LIPA and their branches, if present.

Superior suprarenal, esophageal, gastric and vena caval branches originating from RIPA and LIPA were observed 


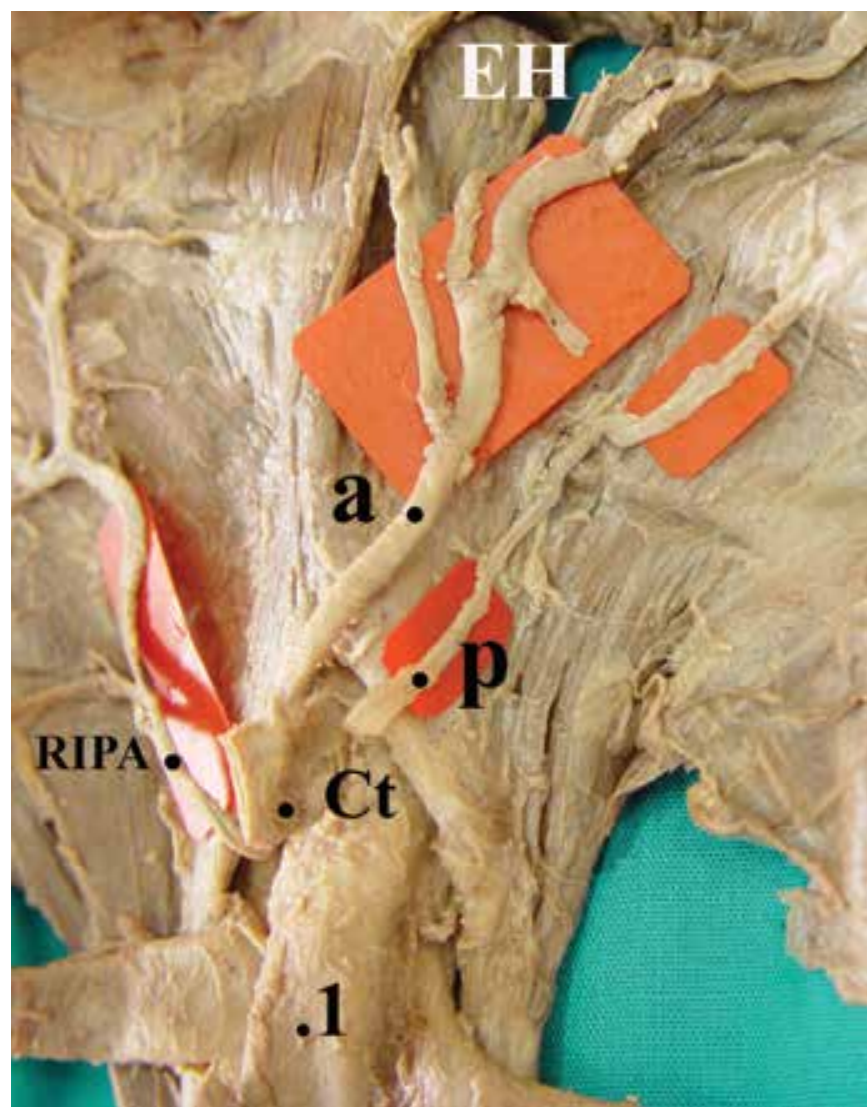

FIG. 3. Separate origins of the ascending (a) and posterior (p) branches of the LIPA from the coeliac trunk $(\mathrm{Ct})$ and abdominal aorta, respectively. The RIPA arises from the abdominal aorta. EH: Esophageal hiatus; 1: Superior mesenteric artery

in all cadavers. Middle suprarenal branches originated from RIPA and LIPA on $8(8 / 26,30.77 \%)$ and $3(3 / 26,11.53 \%)$ sides, respectively.

\section{DISCUSSION}

The origins of both RIPA and LIPA and their frequencies are well known in the literature. Table 2 summarizes the results of the previous studies; ten sides of the present study where the ascending and posterior branches of the LIPA originated separately are excluded from the table in order to simplify the comparison with previous results. However, no major anatomy textbooks, atlases or previous studies with vast sample sizes mentioned that the ascending and posterior branches of LIPA might originate from different sources as individual arteries (8,13-19). Some studies defined these arteries either as accessory left inferior phrenic arteries or cases with a LIPA originating from the RIPA and provided no detail regarding their branches (20-22). Only a few articles have stated that the branches of the LIPA might arise from different sources as individual arteries $(4,23-25)$.

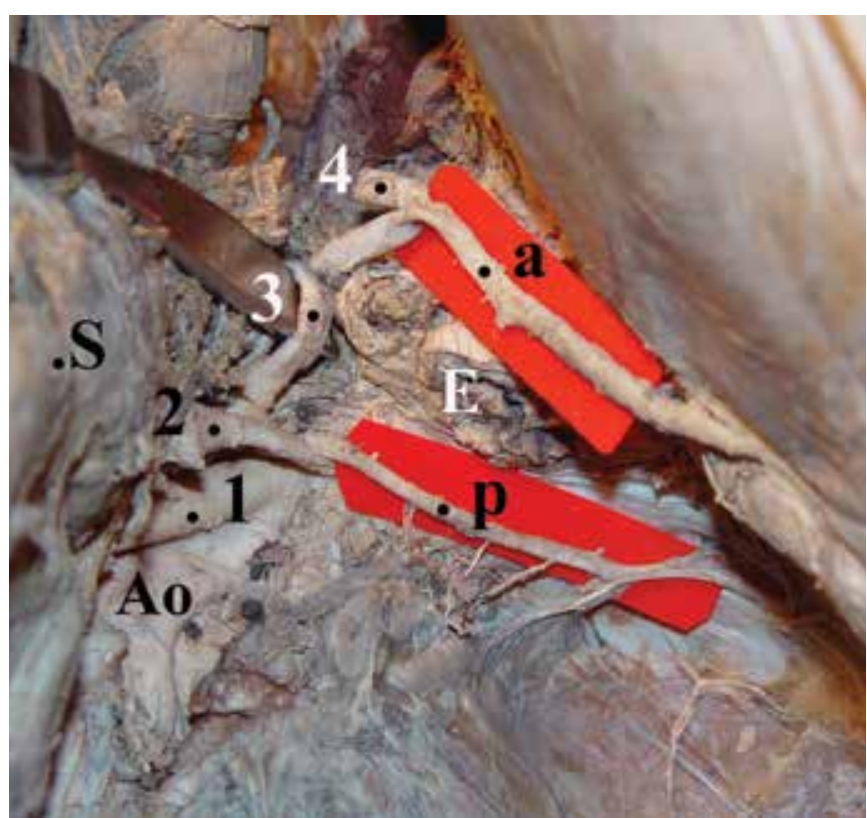

FIG. 4. Separate origins of the ascending (a) and posterior ( $p$ ) branches of LIPA from an accessory left hepatic artery (4) and the coeliac trunk (2) respectively. The accessory left hepatic artery is severed during routine dissection course. E: Esophagus; S: Stomach; Ao: Abdominal aorta; 1: Superior mesenteric artery; 3: Left gastric artery

TABLE 1. The origins of inferior phrenic arteries or their branches (if present) with regard to their sides

\begin{tabular}{|c|c|c|c|c|c|}
\hline \multicolumn{6}{|c|}{ The origins of inferior phrenic arteries and their branches } \\
\hline \multirow{2}{*}{\multicolumn{2}{|c|}{ Origin }} & \multirow{2}{*}{$\begin{array}{l}\text { Right } \\
\text { RIPA }\end{array}$} & \multicolumn{3}{|c|}{ Left } \\
\hline & & & LIPA & aLIPA & pLIPA \\
\hline Common trunk of & Ao & 3 & 3 & & \\
\hline RIPA and LIPA & $\mathrm{Ct}$ & 2 & 2 & & \\
\hline Common trunk of & Ao & 1 & & 1 & \\
\hline $\begin{array}{l}\text { RIPA with branches } \\
\text { of LIPA }\end{array}$ & $\mathrm{Ct}$ & 3 & & & 3 \\
\hline Ao & & 13 & 9 & & 2 \\
\hline $\mathrm{Ct}$ & & 1 & 6 & 1 & 1 \\
\hline LGA & & 1 & & & \\
\hline RRA & & 2 & & & \\
\hline AccLHA & & & & 1 & \\
\hline RIPA & & & & 3 & \\
\hline
\end{tabular}

Total

26

RIPA: Right inferior phrenic artery; LIPA: Left inferior phrenic artery; Ao: Abdominal aorta; Ct: Coeliac trunk; LGA: Left gastric artery; RRA: Right renal artery; AccLHA: Accessory left hepatic artery; aLIPA: Ascending branch of the LIPA; pLIPA: Posterior branch of the LIPA

In their pictorial essay, Miyayama et al. (25) stated that the ascending (anterior) and posterior branches of the LIPA frequently arise from separate origins, without providing any fre- 
TABLE 2. Overview of the previous studies which investigated the anatomy of the inferior phrenic arteries and the present study

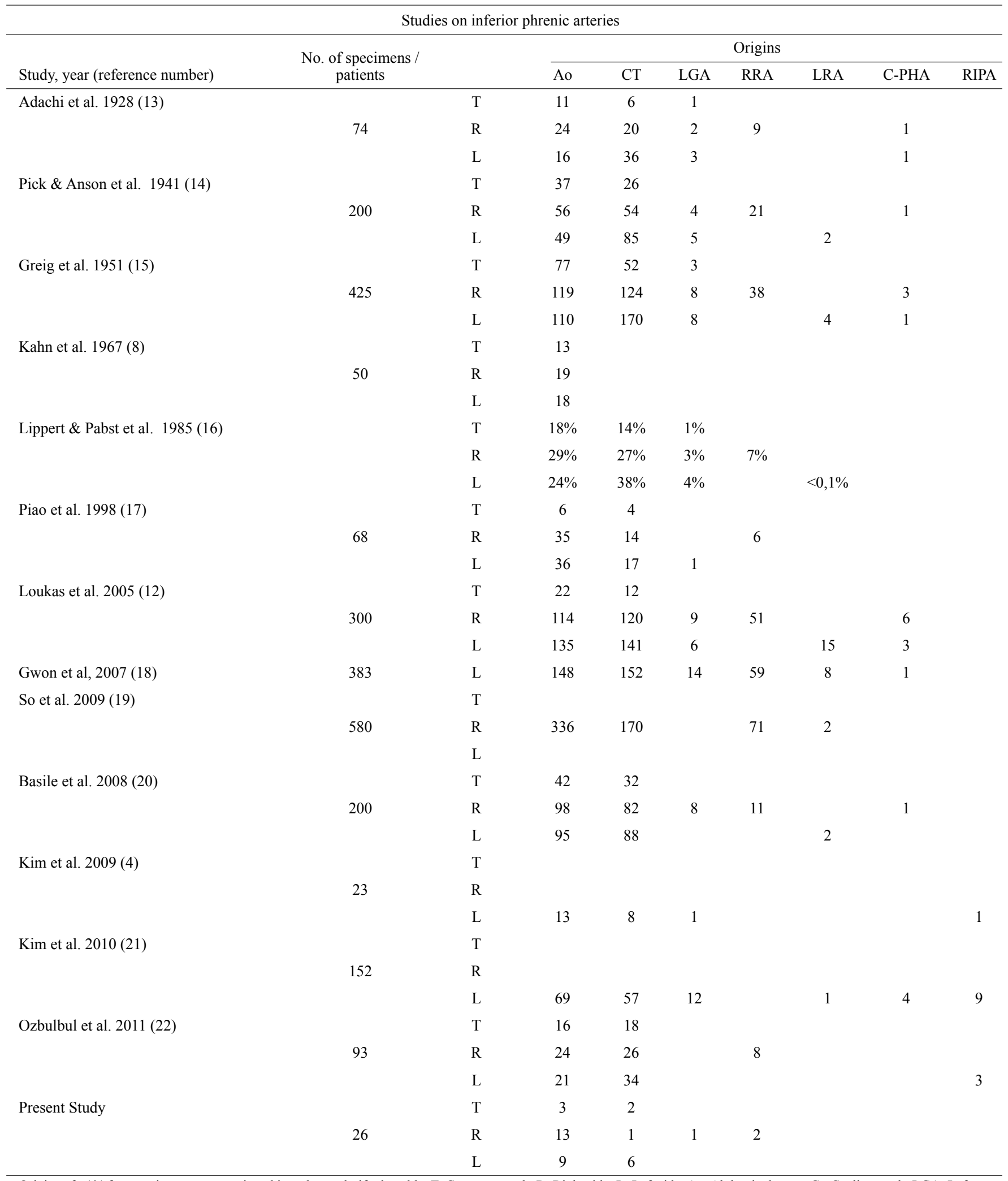


quency or reference. Kim et al. (4) reported a case in a series of 23 patients in which the ascending branch arose from the left gastric artery and the descending (posterior) branch arose from the coeliac trunk. We observed a similar case $(1 / 26$, $3.85 \%$ ) in whom the ascending and posterior branches originated from the coeliac trunk and the aorta, respectively.

In their angiographic study, Tanaka et al. (23) reported 13 patients $(1.7 \%)$ with LIPA arising from the left hepatic or left gastric arteries. For confirmation, they performed one cadaver dissection and stated that the LIPA observed in the angiographies correlated with the ascending (medial) branch of the LIPA, not the LIPA itself; however, they failed to identify the origins of the posterior branches on angiographies (23). We observed one case $(1 / 26,3.85 \%)$ with an ascending branch originating from an accessory left hepatic artery and a posterior branch originating from the coeliac trunk.

Among C-arm CT images of 23 patients, Kim et al. (4) reported a case with an ascending branch originating from RIPA and a posterior (descending) branch from the aorta. Hieda et al. (24) provided the most detailed study about the ascending branch of LIPA originating from the RIPA on 140 patients and gave a frequency of $14.3 \%$. We observed 3 cadavers (3/26, $11.53 \%$ ) in whom the RIPA and the posterior branch of LIPA originated as a common trunk from the coeliac trunk and the ascending branch arose from RIPA. Even with the small sample size, our results, concurring with the results of Hieda et al. (24), show that the ascending branch of the LIPA frequently arises from the RIPA.

Infrequently, the ascending branch may arise with the RIPA as a common trunk as well. Miyayama et al. (25) demonstrated a coeliac arteriogram of a case in whom the ascending (anterior) branch and RIPA arose from the coeliac trunk as a common trunk and the posterior branch originated from the left gastric artery. In one case $(1 / 26,3.85 \%)$, we observed that the posterior branch originated from the abdominal aorta where the RIPA and ascending branch of the LIPA arose from the coeliac trunk as a common trunk.

Complications are to be expected after embolization of the inferior phrenic arteries, due to the introduction of chemical agents into target and non-target arteries. These include: abdominal or referred shoulder pain, pleural effusion, basal atelectasis, hiccups and diaphragm weakness $(3,7,26,27)$. In the literature, diaphragmatic weakness has been limited to the ipsilateral side $(26,27)$. If the ascending branch of the LIPA originating from the RIPA is affected in a patient, severe and bilateral diaphragmatic weakness might occur. Furthermore, gastritis, esophagitis and ulceration might develop if the gastric and esophageal branches of the LIPA are affected (28). Even after RIPA embolization, gastroesophageal complications might manifest if a variant ascending branch of the
LIPA originating from the RIPA is present. The same variation should also be kept in mind if an inferior phrenic artery embolization is being planned for patients with upper gastroesophageal bleeding (9-11).

Among most cases in which the branches of the LIPA originate separately, the course of the ascending branch changes. Tanaka et al. (23) reported that as the ascending branch originated from an accessory left hepatic or an accessory left gastric artery, it traversed anterior to the esophagus rather than behind it. They even named this artery the pre-esophageal branch (23). Hieda et al. (24) observed the same course on 20 patients in whom the ascending branch of the LIPA originated from the RIPA and coursed along the ventral side of the esophagus or stomach. We confirm these observations with 4 cases. It seems that if the ascending branch of the LIPA arises from the RIPA or from an accessory artery within the lesser omentum, its course shifts anterior to the esophagus.

Variations regarding the lateral branches of the abdominal aorta can be explained with the ladder theory proposed by Felix (29). This theory states that the IPAs develop from the cranial group of the lateral mesonephric arteries and variations between other lateral branches (such as the middle suprarenal, renal and gonadal arteries) are possible. However, the coeliac origin and the common trunk of the IPAs originating from the midline aorta as an anterior branch cannot be explained with this theory. Although it has been cited in textbooks and scientific papers for over 100 years, this theory is speculative and has not been verified in vivo (30). According to Isogai et al. (30), at embryonic day 14.0, a few branches from the gonadal artery and/or the abdominal aorta supply the cranial half of the para-aortic ridge which is the adrenal primordium. The most cranial part of these adrenal arteries, which are the prospective IPAs, reaches the diaphragm at the embryonic day 14.3. By the 15th day, the adrenal arteries and eventually the IPAs establish their definitive branching pattern of the adult (30). This new perspective might provide an explanation for the coeliac origin of the IPAs and even its origin as a common trunk from the posterior aspect of the aorta. However, there is not enough evidence in the literature that can enlighten the separate origins of the branches of the IPAs and why this situation is observed on the left side alone, as well as the relocation of the ascending branch anterior to the esophagus in most of these cases.

The small sample size of this study is a limitation. Performing macroscopic dissection as a sole way to obtain data without the intra-arterial injection of latex, silicone or radioopaque medium is another. Despite these limitations, our results are in concordance with a few radiologic reports that provide detailed information regarding the separate origins of 
the branches of LIPA. In the present study, the frequency of separate origins of the branches of LIPA was determined as $23.08 \%$, which had not been reported in the literature before. We also represent 5 cases that have not been reported in the literature previously.

In conclusion, the branches of LIPA frequently originate as separate arteries and when the ascending branch of LIPA arises from RIPA or from an accessory artery within the lesser omentum, its course shifts anterior to the esophagus.

\section{Ethics Committee Approval: N/A.}

\section{Informed Consent: N/A.}

Peer-review: Externally peer-reviewed.

Author contributions: Concept - İ.A.G, Ö.G., A.K.; Design - İ.A.G., Ö.G., A.K.; Supervision - A.Ö., A.U., K.Ş.; Materials İ.A.G., A.Ö., K.Ş.; Data Collection \&/or Processing - İ.A.G., Ö.G., A.Ö.; Analysis \&/or Interpretation - A.K., A.U., K.Ş.; Literature Search - İ.A.G., Ö.G., A.Ö., K.Ş.; Writing - İ.A.G., A.K., A.U.; Critical Reviews - A.Ö., A.U., K.Ş.

Acknowledgements: The authors wish to thank our donor-cadavers whose invaluable gifts made this study possible.

Conflict of Interest: The authors declare no conflict of interests.

Financial Disclosure: The authors have no financial or nonfinancial relationships to disclose.

\section{REFERENCES}

1. Yamada R, Sato M, Kawabata M, Nakatsuka H, Nakamura K, Takashima S. Hepatic artery embolization in 120 patients with unresectable hepatoma. Radiology 1983;148:397-401. [CrossRef]

2. Chuang VP, Wallace S. Hepatic artery embolization in the treatment of hepatic neoplasms. Radiology 1981;140:51-8. [CrossRef]

3. Duprat G, Charnsangavej C, Wallace S, Carrasco CH. Inferior phrenic artery embolization in the treatment of hepatic neoplasms. Acta Radiol 1988;29:427-9. [CrossRef]

4. Kim HC, Chung JW, An S, Seong NK, Jae HJ, Cho BH, et al. Left phrenic artery feeding hepatocellular carcinoma: angiographic anatomy using C-Arm CT. AJR Am J Roentgenol 2009;193:W288-W294. [CrossRef]

5. Kim HC, Chung JW, Lee W, Jae HJ, Cho BH, Park JH. Recognizing extrahepatic collateral vessels that supply hepatocellular carcinoma to avoid complications of transcathater arterial chemoembolization. Radiographics 2005;25:S25-39. [CrossRef]

6. Miyayama S, Matsui O, Taki K, Minami T, Ryu Y, Ito C, et al. Extrahepatic blood supply to hepatocellular carcinoma: angiographic demonstration and transcathater arterial chemoembolization. Cardiovasc Intervent Radiol 2006;29:39-48. [CrossRef]
7. Chung JW, Park JH, Han JK, Choi BI, Kim TK, Han MC. Transcathater oily chemoembolization of the inferior phrenic artery in hepatocellular carcinoma: the safety and potential therapeutic role. J Vasc Interv Radiol 1998;9:495-500. [CrossRef]

8. Kahn PC. Selective angiography of the inferior phrenic arteries. Radiology 1967;88:1-8. [CrossRef]

9. Northrop CH, Studley MA, Smith GR. Hemorrhage from the gastroesophageal junction. A cryptic angiographic diagnosis. Radiology 1975;117:531-2. [CrossRef]

10. Smith DC, Kitching GB. Angiographic demonstration of esophagogastric bleeding from the inferior phrenic artery. Radiology 1977;125:613-4. [CrossRef]

11. Carsen GM, Casarella WJ, Spiegel RM. Transcatheter embolization for treatment of Mallory-Weiss tears of the esophagogastric junction. Radiology 1978;128:309-13. [CrossRef]

12. Loukas M, Hullett J, Wagner T. Clinical anatomy of the inferior phrenic artery. Clin Anat 2005;18:357-65. [CrossRef]

13. Adachi B. Das arterien system der Japaner, Band 2. Kyoto. Keiserlich-Japanischen Universitat 1928; pp.14-16.

14. Pick JW, Anson BJ. The infeior phrenic artery: origin and suprarenal branches. Anat Rec 1940;78:413-27. [CrossRef]

15. Greig HW, Anson BJ, Coleman SS. The inferior phrenic artery: types of origin in 850 body-halves and diaphragmatic relationship. Q Bull Northwest Univ Med Sch 1951;25:345-50.

16. Lippert H, Pabst R. Aortic arch. In: Arterial Variations in Man: Classification and Frequency. Munich, Germany: JF BergmannVerlag 1985;p.24 [CrossRef]

17. So YH, Chung JW, Yin Y, Jae HJ, Jeon UB, Cho BH, et al. The right phrenic artery: origin and proximal anatomy on digital substraction angiography and thin-section helical computed tomography. J Vasc Interv Radiol 2009;20:1164-71. [CrossRef]

18. Basile A, Tsetis D, Montineri A, Puelo S, Saluzzo CM, Runza G, et al. MDCT anatomic assessment of right inferior phrenic artery origin related to potential supply to hepatocellulat carcinoma and its embolization. Cardiovasc Intervent Radiol 2008;31:349-58. [CrossRef]

19. Kim HC, Chung JW, Kim WH, An S, Seong NJ, Jae HJ, et al. Chemoembolization of the left inferior phrenic artery in patients with hepatocellular carcinoma: 9-year single-center experience. AJR Am J Roentgenol 2010;194:1124-30. [CrossRef]

20. Piao DX, Ohtsuka A, Murakami T. Typology of abdominal arteries, with special reference to inferior phrenic arteries and their esophageal branches. Cardiovasc Intervent Radiol 1998;52:189-96.

21. Gwon DI, Ko GY, Yoon HK, Sung KB, Lee JM, Ryu SJ, et al. Inferior phrenic artery: anatomy, variations, pathologic conditions, and interventional management. Radiographics 2007;27:687705. [CrossRef]

22. Ozbulbul NI, Yurdakul M, Tola M. Does the right inferior phrenic artery have a supplying role in liver cirrhosis without hepatocellular carcinoma? A 64-slice CT study. Diagn Interv Radiol 2011;17:239-42.

23. Tanaka R, Ibukuro K, Akita K. The left inferior phrenic artery arising from left hepatic artery or left gastric artery: radiological and anatomical correlation in clinical cases and cadaver dissection. Abdom Imaging 2008;33:328-33. [CrossRef] 
24. Hieda M, Toyota N, Kakiwaza H, Ishikawa M, Horiguchi J, Ito $\mathrm{K}$. The anterior branch of the left inferior phrenic artery: an angiographic and CT study. Cardiovasc Intervent Radiol 2009;32:250-4. [CrossRef]

25. Miyayama S, Yamashiro M, Yoshie Y, Okuda M, Nakashima $\mathrm{Y}$, Ikeno $\mathrm{H}$, et al. Inferior phrenic arteries: angiographic anatomy, variations, and catheterization tecniques for transcatheter arterial chemoembolization. Jpn J Radiol 2010;28:50211. [CrossRef]

26. Shin SW, Do YS, Choo SW, Lieu WC, Cho SK, Park KB, et al. Diaphragmatic weakness after transcatheter arterial chemoembolization of inferior phrenic artery for treatment of hepatocellular carcinoma. Radiology 2006;241:581-8. [CrossRef]

27. Lee DH, Chung JW, Kim HC, Jae HJ, Yoon CJ, Kang SG, et al. Development of diaphragmatic weakness after transcath- eter arterial chemoembolization of the right inferior phrenic artery: frequency and determinent factors. $J$ Vasc Interv Radiol 2009;20:484-9. [CrossRef]

28. Chung JW, Park JH, Han JK, Choi BI, Han MC, Lee HS, et al. Hepatic tumors: predisposing factors for complications of transcatheter oily chemoembolization. Radiology 1996;198:33-40. [CrossRef]

29. Felix W. The mesonephric arteries. In: Kiebel F and Mall FP (eds). Manual of human embryology. Volume 2. Philadelphia: J. B. Lippincott Company 1912;pp.820-5.

30. Isogai S, Horiguchi $\mathrm{M}$, Hitomi J. The para-aortic ridge plays a key role in the formation of renal, adrenal and gonadal vascular systems. J Anat 2010;216:656-70. [CrossRef] 